\title{
Morphometric analysis of scapula to determine sexual dimorphism
}

Shailesh M. Patel, Mitesh A. Shah, Rakesh K. Vora, Jatin B. Goda, Suresh P. Rathod ${ }^{1}$, Shaival Shah ${ }^{2}$

Department of Anatomy, Government Medical College, Bhavnagar, ${ }^{1}$ Anatomy, P.D.U. Medical College, Rajkot, Gujarat,

${ }^{2}$ Anatomy, B.J. Medical College,

Ahmedabad, Gujarat, India.

Address for the Correspondence:

Dr. Shailesh M. Patel, Department of Anatomy, Government Medical College, Bhavnagar - 364 001, Gujarat, India.

E-mail: dr_smpatel@yahoo.com

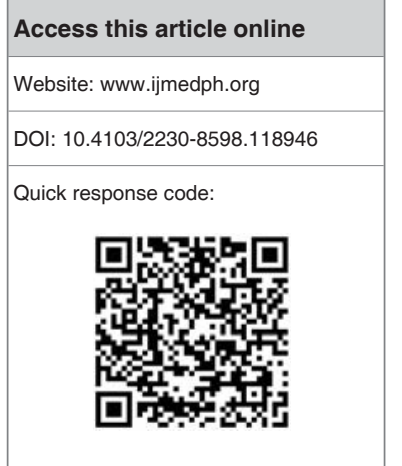

Background and Objectives: Identification of the sex of an individual is important in determining, the identity from the available parts of skeleton. Aims: To derive a logistical regression formula for sex determination of Indian population, using dimensions of scapula. Materials and Methods: Thirty one adult scapulae (20 males and 11 females) were used in the study. Scapulae were measured in millimetre for $\mathrm{MSH}, \mathrm{MSB}, \mathrm{GCH}$ and GCB with the help of the sliding calliper. The logistical regression equation was derived from these measurements. Results: Among all parameters, MSB found to be most significant $(P \leq 0.001)$. For the regression equation incorporating all for Scapular dimensions, the logistic regression score $(\mathrm{Y})$ is calculated as follow: $\mathrm{Y}=(-0.246 * \mathrm{MSH})+(0.122 * \mathrm{MSB})+(-0.486 * \mathrm{GCH})+(-0.034 * \mathrm{GCB})+35.356$. Conclusion: The results of this study are very useful for sex determination in medicolegal cases where the skulls and pelvic bones are damaged or not available. In this study, population specific logistic regression formula is derived by combination of parameters, which can be helpful for sex determination in Indian populations.

Key words: Glenoid cavity, scapula, Sex determination

\section{INTRODUCTION}

In forensic and medicolegal cases, sex determination is vital to establish identity of an individual. For this purpose, essential bones of skeleton should be available complete and undamaged. Skull, pelvis, long bones, clavicle, patella, sacrum, sternum are the bones on which, studies have been done to determine the sex. ${ }^{[1-7]}$

Skull and pelvis are most frequently utilized for the sex determination. However, there is a disadvantage of using skulls and pelvis for sex determination as they do not provide reliable results when they are damaged. The other bones mentioned above are often missing or found incomplete during forensic examinations.

Scapula is mostly obtained in intact condition compared to the other bones. Determining the sex of an individual is possible when we apply appropriate statistical methods using scapular measurements [Figures 1 and 2]. Determination of sex using scapular measurements is very useful in medicolegal cases, natural disasters and in certain circumstances in which traditionally used bones of skeleton are either absent or fragmented.

\section{MATERIALS AND METHODS}

This study was conducted using 31 adult skeletons (20 males and 11 females) with closed epiphysis having intact and well-preserved scapulae. These skeletons of known sexes were taken from Dept. Of Anatomy, Govt. Medical College, Bhavnagar, Gujarat, India.

Following parameters of scapula were measured with the help of sliding calliper. All measurements were taken in millimetre.

\section{Maximum scapular height}

Maximum distance between the highest point of the superior angle and the lowest point of the inferior angle. 


\section{Maximum scapular breadth}

Maximum distance between the point on the longitudinal axis of the glenoid cavity and the point on the prolongation of the inferior boundary of the dorsal margin of the spine.

\section{Glenoid cavity height}

Maximum distance from the inferior point of the glenoid margin to the most prominent point of the supraglenoid tubercle.

\section{Glenoid cavity breadth}

Maximum breadth of the articular margin, perpendicular to the glenoid cavity height.

Data are statistically analyzed and results are tabulated.

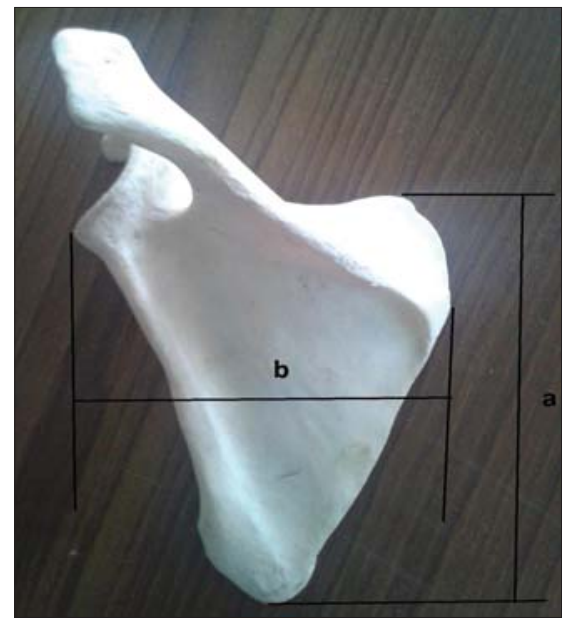

Figure 1: Method of measurement of Scapular length and breadth. $a=$ maximum scapular height, $b=$ maximum scapular breadth
Descriptive statistics were calculated, and a student t-test for equal variances was applied to assess the difference between the means of the male versus female groups.

\section{RESULTS}

Table 1 shows mean of the MSH, MSB, GCH and GCB, their standard deviation, standard error mean, $t$-value and $P$ value for both males and females. There was a highly significant difference $(P<0.001)$ between male and female for the mean value of all measurements except GCB. So it indicates the existence of strong sexual dimorphism in scapula.

With the help of SPSS software, the logistical regression equation was derived from stepwise method which is shown in Table 2. By

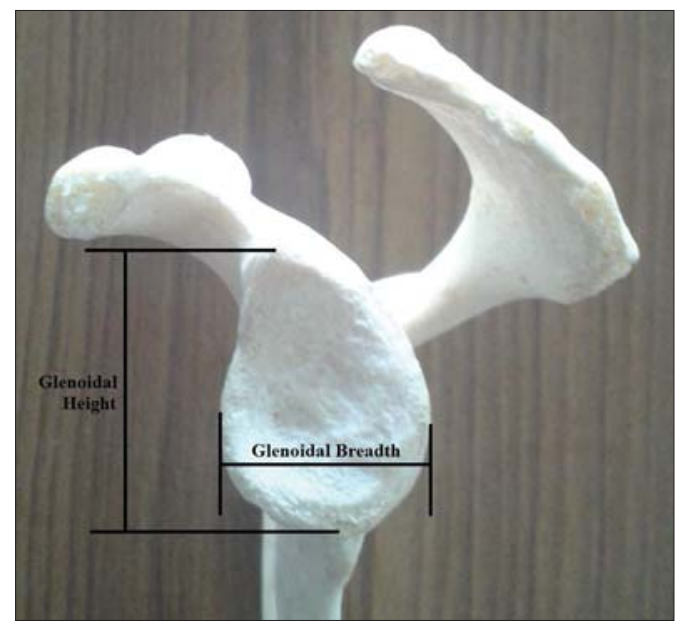

Figure 2: Method of measurement of the Glenoidal length and Glenoidal breadth

\begin{tabular}{|c|c|c|c|c|c|c|c|}
\hline & Sex & $n$ & Mean & Std. deviation & Std. error mean & $t$ value & $P$ value \\
\hline \multirow[t]{2}{*}{$\mathrm{MSH}$} & Male & 40 & 136.0342 & 11.49134 & 1.81694 & 5.812 & 0.000 \\
\hline & Female & 22 & 119.6327 & 8.81377 & 1.87910 & & \\
\hline \multirow[t]{2}{*}{ MSB } & Male & 40 & 100.6710 & 8.51321 & 1.34606 & 3.673 & 0.001 \\
\hline & Female & 22 & 93.5173 & 4.38883 & 0.93570 & & \\
\hline \multirow[t]{2}{*}{$\mathrm{GCH}$} & Male & 40 & 34.6398 & 3.59028 & 0.56767 & 4.136 & 0.000 \\
\hline & Female & 22 & 31.2873 & 1.64449 & 0.35061 & & \\
\hline \multirow[t]{2}{*}{ GCB } & Male & 40 & 23.895 & 2.2904 & 0.3622 & 2.572 & 0.013 \\
\hline & Female & 22 & 22.220 & 2.7295 & 0.5819 & & \\
\hline
\end{tabular}

MSH=Maximum scapular height, MSB=Maximum scapular breadth, GCH=Glenoid cavity height, GCB=Glenoid cavity breadth

\begin{tabular}{|c|c|c|c|c|c|c|}
\hline \multirow[t]{2}{*}{ Variable } & \multirow[t]{2}{*}{$\beta$ coefficient } & \multirow[t]{2}{*}{ S.E. } & \multirow[t]{2}{*}{ Significance } & \multirow[t]{2}{*}{$\operatorname{Exp}(B)$} & \multicolumn{2}{|c|}{ 95.0\% C.I. for EXP (B) } \\
\hline & & & & & Lower & Upper \\
\hline $\mathrm{MSH}$ & -0.246 & 0.083 & 0.003 & 0.782 & 0.664 & 0.921 \\
\hline MSB & 0.122 & 0.090 & 0.176 & 1.130 & 0.947 & 1.349 \\
\hline $\mathrm{GCH}$ & -0.486 & 0.310 & 0.117 & 0.615 & 0.335 & 1.130 \\
\hline GCB & -0.034 & 0.243 & 0.889 & 0.967 & 0.601 & 1.555 \\
\hline Constant & 35.356 & 10.800 & 0.001 & $2.263 \mathrm{E} 15$ & & \\
\hline
\end{tabular}

MSH=Maximum scapular height, MSB=Maximum scapular breadth, GCH=Glenoid cavity height, GCB=Glenoid cavity breadth 
multiplying the value of each dimension with its corresponding coefficient ( $\beta$ coefficient) and adding the products together along with the appropriate constant, the sex of a specimen can be determined. For the regression equation incorporating all for Scapular dimensions, the logistic regression score $(\mathrm{Y})$ is calculated as follow:

$$
\begin{array}{r}
\mathrm{Y}=(-0.246 * \mathrm{MSH})+(0.122 * \mathrm{MSB})+(-0.486 * \mathrm{GCH})+(-0.034 \\
* \mathrm{GCB})+35.356
\end{array}
$$

The accuracy for the Univariate regression equation for MSB is highest and most significant Figure 3.

\section{DISCUSSION}

After taking measurements of scapula described in materials and methods section, the resulting data of measurement was subjected to logistic regression analysis in order to develop population specific standards for sex determination as described in results section. ${ }^{[8]}$ The derived regression equations yielded correct classification accuracy rates. Therefore, scapula is having a great importance in gender identification of unknown person in Indian population. As mentioned, among all the 4 parameters, scapular breadth was most significant.

Dabbs G. reported $84-88 \%$ accuracy using maximum length of scapula, maximum length of scapular spine, breadth of infraspinous body, height and breadth of the glenoid fossa. ${ }^{[9]} \mathrm{P}$. James Macaluso Jr. Reported $88.3 \%$ success rate for area of the glenoid fossa and $85.8 \%$ success rate for glenoid fossa breadth. ${ }^{[10]}$ Y Scoltz found $>91 \%$ accuracy for female and $>95 \%$ accuracy for male in his study. ${ }^{[11]}$ Ozer reported $82.9 \%-95 \%$ accuracy with highest accuracy for maximum scapular breadth. ${ }^{[12]}$

Previous studies suggested that use of multiple variables give higher accuracy compared to the studies using single variable. The formula obtained using four variables (MSH, MSB, GCH, GCB) was highly reliable. It has to be kept in mind that sometimes it is possible that all the measurements are not available if the scapula is not intact. Because the mean scapular breadth measurements show highest accuracy rates amongst all the four parameters measured in the study, it may be having a great importance considering scapula an easily fragmented bone. It is to mention that MSB showed more reliable values over other parameters.

The current study yielded that, accuracy of sex determination from scapula can be improved by deriving logistic regression score $(\mathrm{Y})$ from 4 scapular measurements. Among the four measurements, MSB is the most significant parameter. Findings of this study are comparable to the findings of other studies utilizing the scapular measurements. This study confirmed that scapula has high value of accuracy to determine gender in Indians.

\section{CONCLUSION}

The results of this study are very useful for sex determination in forensic anthropological and medicolegal cases where skull and

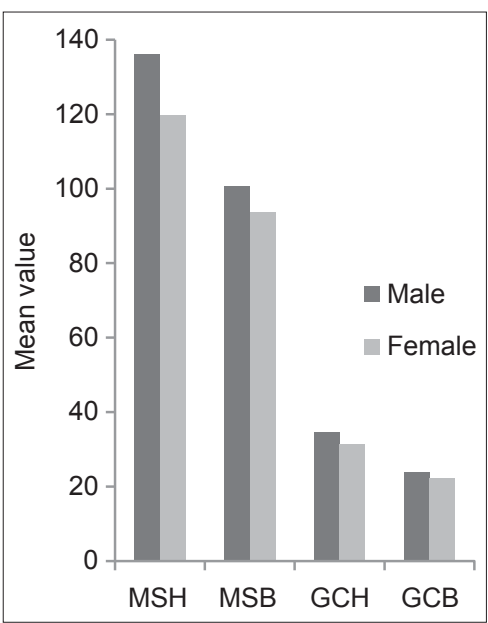

Figure 3: Comparison of $\mathrm{MSH}, \mathrm{MSB}, \mathrm{GCH}$ and $\mathrm{GCB}$ in male and female

pelvic bones are unavailable or damaged. The present study has confirmed that gender can be determined with high accuracy by use of scapular measurements. Accuracy of sex determination can be improved by obtaining logistic regression score $(\mathrm{Y})$ from four scapular measurements (MSH, MSB, GCH and GCB). The present study confirmed that MSB alone as well as combination of all four parameters are good discriminators. In this study, population specific logistic regression formula is derived which is helpful for sex determination in Indians.

\section{ACKNOWLEDGMENT}

We gratefully acknowledge to Dr. Vikash Doshi, Assistant Professor, Dept. of PSM, Govt. Medical College, Vadodara, for support and statistical assistance.

\section{REFERENCES}

1. Singh G, Talwar I. Morphometric analysis of foramen magnumin human skull for sex determination. Hum Biol Rev 2013;2:29-41.

2. Pal GP, Bose S, Choudhary S. Reliability criteria used for sexing of hip bones. J Anat Soc India 2004;53:2.

3. Richman EA, Mitchel ME, Schulter-Ellis FP, Corruccini RS. Determination of sex by Discriminant function analysis of postcranial skeletal measurements. J Forensic Sci 1979;24:159-67.

4. Haque MK, Mansur DI, Krishnamurthy A, Karki R, Sharma K, Shakya R. Morphometric Analysis of clavicle in Nepalese population. Kathmandu Univ Med J. 2011;9:193-7.

5. Akhlaghi M, Sheikhazadi A, Naghsh A, Dorvashi G. Identification of sex in Iranian population using patella Dimensions. J Forensic Leg Med 2010;17:150-5.

6. Arora AK, Gupta P, Mahajan S,Kapoor SS. Significance of Sacral index in estimation of sex in sacra of cadavers in Punjab. J Indian Acad Forensic Med 32 (2),2010;104-7.

7. Mukhopadhyay PP. Determination of Sex from Adult Sternum by Discriminant Function Analysis on Autopsy Sample of Indian Bengali Population: A New Approach. J Indian Acad Forensic Med 32 (4), 2010; 321-4.

8. Macaluso PJ Jr. Sex discrimination from the acetabulum in a twentieth-century skeletalsample from France using digital photogrammetry. Homo 2011;62:44-55.

9. Dabbs G. Sex determination using the scapula in New Kingdom skeletons from Tell El-Amarna. Homo 2010;61:413-20. 
10. Macaluso PJ Jr. Sex determination from the glenoid cavity in black South Africans: Morphometric analysis of digital photographs. Int J Legal Med 2011;125:773-8.

11. Scholtz $Y$, Steyn M, Pretorius M. A geometric morphometric study into the sexual dimorphism of the human scapula. Homo 2010;61:253-70.

12. Ozer I, Katayama K, Sagir M, Gulec E. Sex determination using scapula in medieval skeletons from East Anatolia. Coll Antroprol 2006;2:415-9.
How to cite this article: Patel SM, Shah MA, Vora RK, Goda JB, Rathod SP, Shah S. Morphometric analysis of scapula to determine sexual dimorphism. Int J Med Public Health 2013;3:207-10.

Source of Support: Nil, Conflict of Interest: None declared. 